\title{
Criminosos em série e a dinâmica metropolitana na RMBH
}

\author{
Serial criminals and the metropolitan dynamics in the RMBH
}

\author{
Antônio Hot Pereira de Faria \\ Capitão PMMG - Batalhão de Rondas Táticas Metropolitanas \\ Doutor em Geografia pela PUC Minas, Brasil \\ hot.pmmg@gmail.com
}

Alexandre Magno Alves Diniz

Prof. Programa de Pós-Graduação em Geografia PUC Minas, Brasil

alexandremadiniz@gmail.com

\begin{abstract}
Resumo
O objetivo central do artigo é analisar a dinâmica metropolitana no cometimento de delitos a partir da verificação de eventos perpetrados por infratores em série, de forma a identificar se há participação relevante de infratores residentes em municípios pertencentes à Região Metropolitana de Belo Horizonte no cometimento de delitos na capital mineira. Trata-se de uma pesquisa quantitativa, a qual utilizou dados oficiais de criminalidade (boletins de ocorrência policial) com recorte temporal de 2011 a 2013. Considerando o objetivo do trabalho de análise de casos individuais, foi feita a seleção dos indivíduos considerados como criminosos em série, por meio de registros policiais de delitos cometidos de maneira reiterada, por um mesmo autor em ao menos 04 boletins de ocorrência no período, tendo como recorte espacial de delitos no município de Belo Horizonte. Foram estudados 1259 delitos perpetrados por 114 indivíduos. Os resultados demonstram que a Região Metropolitana de Belo Horizonte $(\mathrm{RMBH})$ possui uma representatividade alta em termos de base operacional de infratores atuantes na capital, corroborando com dados que indicam a integração alta ou muito alta dos municípios da região metropolitana. Destaca-se o aspecto de mobilidade pendular, que aliado aos principais motivos (trabalho e estudo), também se torna representativo em termos de cometimento de delitos. Esse aspecto contribui para a explicação do delito por meio da teoria das atividades rotineiras, em que as atividades corriqueiras da população acabam por moldar o comportamento criminal, ou seja, acompanha a tendência de mobilidade da região metropolitana para a capital por motivos legítimos (trabalho e estudo).
\end{abstract}

Palavras-chave: Criminosos em série; Mobilidade Pendular; Atividades Rotineiras; Região Metropolitana.

\begin{abstract}
The main objective of the article is to analyze the metropolitan dynamics in committing crimes based on the verification of events perpetrated by serial offenders, to identify if there is relevant participation of offenders living in municipalities belonging to the Metropolitan Region of Belo Horizonte in committing crimes. in the capital. This is quantitative research, which used official crime data (police reports) with a time frame from 2011 to 2013. Considering the purpose of the analysis of individual cases, the selection of individuals considered here as criminals were made habitual (police records of crimes committed repeatedly by the same author) in at least 04 police reports in the period, with the spatial cut-off of crimes in the city of Belo Horizonte. One thousand two hundred fifty-nine crimes perpetrated by 114 individuals were studied. The results demonstrate that the Metropolitan Region of Belo Horizonte (RMBH) has high representativeness in terms of the operational base of offenders operating in the capital, demonstrating that there is a high or very high integration of the municipalities in the metropolitan region. The aspect of pendular mobility stands
\end{abstract}


out, which, together with the main reasons (work and study), also becomes representative in terms of committing crimes. This aspect contributes to the explanation of the crime through the theory of routine activities, in which the ordinary activities of the population end up shaping criminal behaviour, that is, it accompanies the tendency of mobility from the metropolitan region to the capital for legitimate reasons (work and study) the same situation can also occur for illegal activities.

Keywords: Serial criminals; Pendular mobility; Routine Activities.

\section{INTRODUÇÃO}

O Brasil vivenciou no período pós-guerra intenso e concentrado processo de urbanização, fruto da adoção de projeto de desenvolvimento arquitetado pelos capitais nacional e estrangeiro e o Estado brasileiro, com o fim de promover a diversificação econômica, com ênfase na criação de estímulos para a industrialização (RIBEIRO et al., 2012). Este processo dual (urbanizaçãoindustrialização) promoveu a integração econômica e do mercado nacional, gerando uma divisão inter-regional do trabalho que acirrou as desigualdades espaciais preexistentes (CARVALHO et al., 2001). A intensificação das desigualdades regionais, por sua vez, desencadeou nos anos 1970 e 1980 volumosos fluxos migratórios internos, transferindo hordas de trabalhadores das zonas rurais para as urbanas, bem como das unidades da federação economicamente deprimidas e estagnadas na direção das grandes metrópoles, reconcentrando vasto contingente demográfico nos grandes aglomerados metropolitanos (BRITO; SOUZA, 2005). Esse processo, por sua vez, impactou de forma substantiva o espaço urbano metropolitano, desencadeando severos danos ao meio ambiente, baixa qualidade de vida, miséria social e violência (MARICATO, 1995; 1996), gerando uma condição paradoxal: crescimento econômico e expansão das desigualdades sociais, com forte concentração espacial da pobreza (MARICATO, 2003).

Neste sentido, cabe destacar que "a metropolização não consiste, a rigor, em um fenômeno, trata-se de um processo histórico que expressa a estrutura, a forma e a dinâmica socioespacial de um território", segundo a lógica do sistema de produção (BALBIM et al., 2012, p.151). Além das diferenças socioespaciais, as regiões metropolitanas são compostas por núcleos articulados morfológica e funcionalmente, que operam de modo complementar, nas quais grandes infraestruturas urbanas operam como elemento agregador do território metropolitano, organizando os sistemas e subsistemas urbanos, organizando os fluxos que evitam a dispersão funcional (MEYER, 2000). Portanto, além de apresentar forte conurbação das cidades que compõem o aglomerado metropolitano, este é composto por unidades contíguas, articuladas pela infraestrutura de transportes e comunicações, apresentando intensas interações entre os núcleos urbanos que compõem o tecido metropolitano. Essas cidades se articulam através de uma hierarquia, sendo a 
primazia urbana exercida pelas capitais de unidades da federação, ou núcleos metropolitanos (BRITO, 2007).

Em décadas mais recentes, assiste-se no conjunto de espaços metropolitanos brasileiros a algumas macrotendências dignas de nota. De um lado, a significativa redução do ritmo de crescimento dessas áreas (PINHO; BRITO, 2013); e de outro, a forte tendência à desconcentração de atividades econômicas das metrópoles para as demais municipalidades metropolitanas. Este último processo tem-se dado graças às pressões do mercado imobiliário, juntamente com a ação seletiva do Estado. Conjugadas, essas duas macrotendências vêm promovendo renovada redistribuição espacial da população no contexto das regiões metropolitanas, fazendo com que os municípios periféricos cresçam a um ritmo mais acentuado do que os núcleos metropolitanos. Essa reestruturação, por sua vez, tem outro importante efeito sobre a dinâmica metropolitana: a intensificação da mobilidade pendular intrametropolitana (BRITO; SOUZA, 2005a; 2005b), tendo em vista o fato de que a metrópole permanece concentrando boa parte do emprego e de importantes equipamentos urbanos.

Neste estudo, volta-se a atenção para a mobilidade pendular, dada a sua intrínseca associação com o processo de metropolização. Este tema vem sendo explorado em diversas regiões metropolitanas brasileiras (MOURA et al., 2005; ACCIOLY; NOGUEIRA, 2011; LOBO; GARCIA; PINTO, 2015; DELGADO et al., 2016; por exemplo), uma vez que as dimensões espacial e temporal desses fluxos trazem importantes elementos para a compreensão dos processos de dispersão e concentração espacial demográfica e das forças produtivas. Destaque-se, ainda, que a mobilidade pendular intrametropolitana se configura como um importante indicador do grau de interação municipal ao espaço regional metropolitano (LOBO et al., 2017), oferecendo subsídios à formulação de políticas públicas, especialmente aquelas associadas à mobilidade, habitação, trabalho, infraestrutura e serviços públicos (MOURA et al., 2013).

Observa-se ao longo das últimas décadas na Região Metropolitana de Belo Horizonte o exercício dessas duas macrotendências apontadas anteriormente, quais sejam: a redução nos ritmos de crescimento da metrópole, juntamente com a intensificação do crescimento populacional nos demais municípios metropolitanos, acompanhada da intensificação da mobilidade pendular. São numerosos os estudos voltados para a mobilidade intrametropolitana na RMBH (BRITO; SOUZA, 2005a; BRITO; SOUZA, 2005b; SOUZA; BRITO, 2006; SOARES, 2006; MIRANDA; DOMINGUES, 2010; PINHO; BRITO, 2013; COMINI et al., 2014; LOBO et al., 2017), no entanto esta literatura está focada, principalmente, no exame de movimentação pendular com a finalidade de trabalho ou estudo, ignorando sistematicamente uma importante faceta das trocas intrametropolitanas: a dinâmica criminal. Retomando as assertivas de Maricato (1995; 1996), o processo de metropolização engendrou um tecido metropolitano marcado por significativos 
impactos sociais e ambientais, desencadeando severos danos ao meio ambiente, baixa qualidade de vida, miséria social e violência. Esta última dimensão vem sendo consistentemente ignorada pela literatura, sendo imperativo lançar luz sobre a relação entre a dinâmica metropolitana, especialmente aquela associada aos movimentos pendulares, e a ocorrência criminal. Em que medida os criminosos em série se utilizam da conectividade intrametropolitana para a sua ação criminal? Qual a relação entre os níveis de integração metropolitana e a dinâmica criminal?

O presente estudo busca lançar luz sobre essas questões, tendo como objetivo central a dinâmica metropolitana no cometimento de delitos a partir da verificação de eventos perpetrados por infratores em série, de forma a identificar se há participação relevante de infratores residentes em municípios pertencentes à Região Metropolitana de Belo Horizonte no cometimento de delitos na capital mineira.

Para contribuir em termos teóricos a partir da Criminologia Ambiental, essa perspectiva de análise amolda-se às teorias de oportunidade dentre as quais destaca-se a teoria das atividades rotineiras e teoria do padrão do crime.

De acordo com a teoria das atividades rotineiras, o crime é resultado da convergência de três elementos no tempo e no espaço: a presença de ofensor provável ou motivado; a disponibilidade de alvos em potencial; e a ausência de guardiões capazes de prevenir o ato criminal (COHEN; FELSON, 1979).

Um provável ofensor inclui qualquer um com uma inclinação para cometer um crime (FELSON, 1983). Um alvo em potencial abarca alguma pessoa ou bem que suscite a ação de um criminoso, que inclua o valor real (monetário e/ou simbólico) do alvo e o seu desejo pelos infratores, a visibilidade aos infratores ou seus informantes, o acesso a ela, a facilidade de escapar do local, bem como a portabilidade ou mobilidade de objetos procurados pelos ofensores (FELSON, 1983). Segundo Eck; Weisburd (1995), o guardião é uma pessoa capaz de proteger o alvo, incluindo amigos, pessoas próximas (parentes, professores, empregados), gestores (zeladores), além das autoridades formais como a polícia e seguranças pessoais.

O termo "atividades rotineiras" significa:

[...] quaisquer atividades recorrentes que supram as necessidades básicas individuais e da população, independentemente das suas origens biológicas ou culturais [...], incluindo o trabalho formalizado, o lazer, a interação social, a aprendizagem [...] que ocorrem em casa, nos postos de trabalho e em outras atividades fora de casa (COHEN, FELSON, 1979, p. 593, tradução nossa).

Já a teoria do padrão do crime é uma combinação do trabalho de muitas partes de um movimento alternativo em criminologia, que se concentra no próprio evento criminoso ou em padrões de crime e comportamento criminal, incluindo: teoria de escolha racional, teoria da 
atividade rotineira, criminologia ambiental, análise estratégica e teoria do estilo de vida / exposição. Inclui também a aplicação de outras ideias, como prevenção situacional da criminalidade, análise de hot spots e teorias de oportunidade (BRANTINGHAM; BRANTINGHAM, 1981, 1984, 1991).

Brantingham e Brantingham (1993) desenvolveram a teoria do padrão do crime a fim de descrever os processos pelos quais um evento criminal ocorre. Ele inicia com uma pessoa agindo ou se comportando de alguma forma, incluindo participação em atos ou comportamentos legítimos. Com o surgimento de algum evento/fato é desencadeada a vontade em cometer um ato criminoso. O fato/evento iniciador conduz a busca do ofensor, que pode ser mínimo ou mais amplo, dependendo de alguns fatores como, por exemplo, o quão bem o infrator conhece a área. Esta busca, dependendo da avaliação de alvos disponíveis, pode resultar num evento criminal.

Há três conceitos principais presentes na teoria do padrão do crime, são eles: nós, caminhos e fronteiras. Os nós referem-se aos locais para onde as pessoas vão e de onde elas vêm (destino e origem), por exemplo: residência, trabalho, lojas, etc. Caminhos compreendem os principais trajetos percorridos entre os nós, como as ruas, calçadas, utilizadas nos trajetos etc. Já as fronteiras ou limites/bordas são as circunscrições das áreas ocupadas pelas pessoas no desenvolvimento de suas atividades (vizinhança, comunidade, cidade, etc.).

A justificativa do trabalho reside no fato de que, da mesma forma que indivíduos se deslocam de municípios circunvizinhos diariamente para realizarem atividades lícitas como trabalho e educação num contexto metropolitano, também ocorre a mobilidade pendular de infratores. Esta verificação visa alertar para o fato de que as estratégias de prevenção e repressão criminal devem focar além das áreas delimitadas pela regionalização existente nos órgãos de segurança pública, uma vez que o espaço de ação de infratores e seus deslocamentos não se restringem em áreas definidas formalmente. Assim, podem-se aperfeiçoar as políticas públicas de segurança que visem um atendimento mais adequado aos cidadãos-usuários dos serviços tanto nos municípios-sede de residência como destinatários dos deslocamentos, bem como dos trajetos utilizados.

\section{A CIDADE COMO PONTO: análise da posição de Belo Horizonte no contexto regional}

Belo Horizonte, em relação ao espaço do estado de Minas Gerais, apresenta uma posição de centralidade, o que contribuiu sobremaneira para sua melhor integração regional.

A Região Metropolitana de Belo Horizonte (RMBH) foi criada em 1973 como resultado do crescimento espacial da cidade, cujos contornos se encontraram com os municípios vizinhos, conferindo-lhe feições metropolitanas já a partir da década de 1950 (CARVALHO, 1989). 


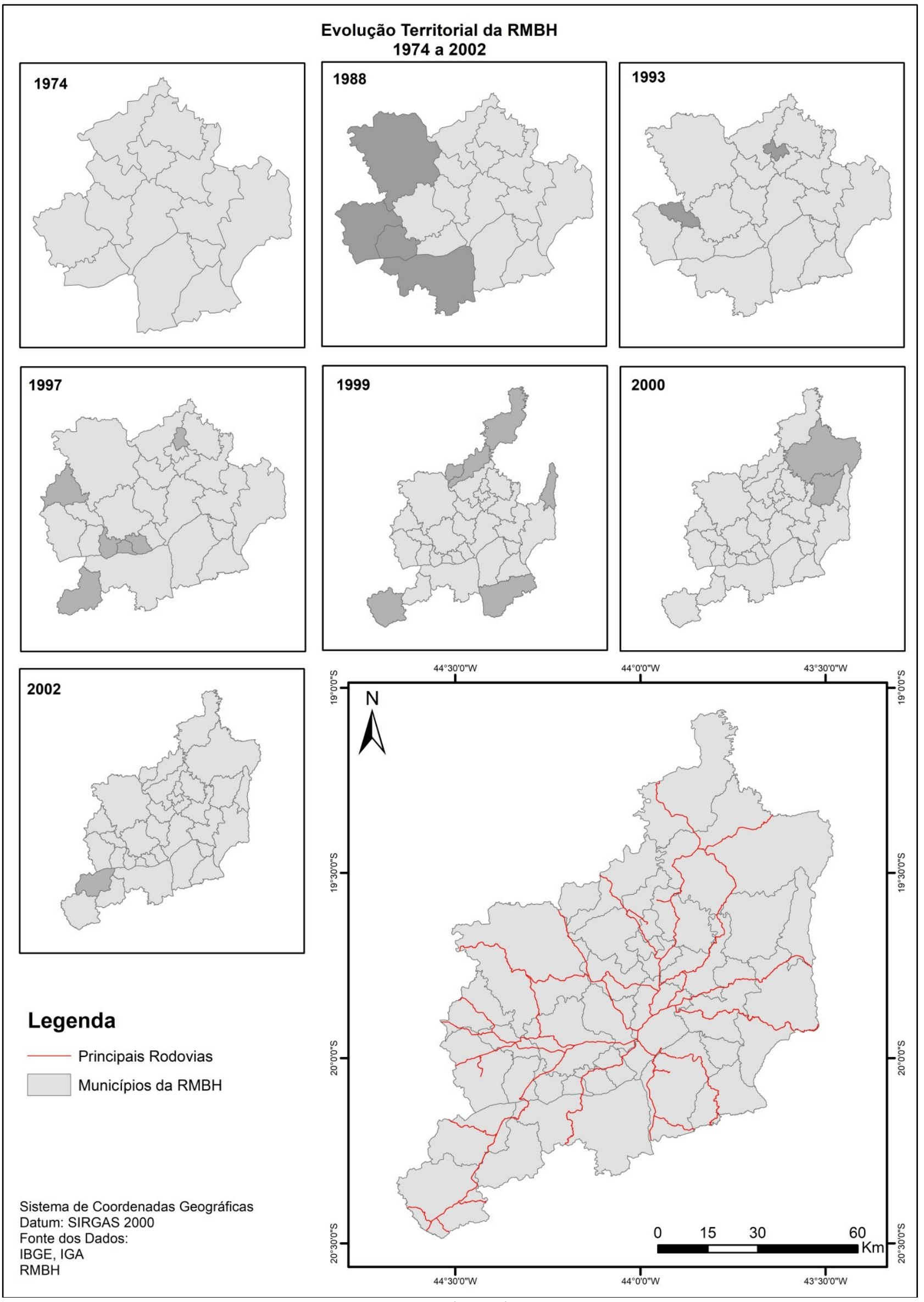

Figura 1 - Evolução da RMBH.

Fonte: Andrade; Mendonça; Diniz (2015, p. 32). 
Atualmente a RMBH conta com 34 municípios mais 14 em seu colar, somando 48 municípios.

Numa análise dos graus de integração entre os municípios que compõem a RMBH, o Observatório das Metrópoles, realizou um estudo, cujos resultados estão sintetizados a seguir:

Tabela 1 - Relação de municípios por nível de integração metropolitana.

\begin{tabular}{|c|c|c|}
\hline Municípios & 2000 & 2010 \\
\hline Baldim & Muito Baixo & Muito Baixo \\
\hline Belo Horizonte & Polo & Polo \\
\hline Betim & Muito Alto & Muito Alto \\
\hline Brumadinho & Baixo & Médio \\
\hline Caeté & Médio & Médio \\
\hline Capim Branco & Baixo & Médio \\
\hline Confins & Baixo & Alto \\
\hline Contagem & Muito Alto & Muito Alto \\
\hline Esmeraldas & Médio & Alto \\
\hline Florestal & Muito Baixo & Baixo \\
\hline Ibirité & Alto & Muito Alto \\
\hline Igarapé & Baixo & Alto \\
\hline Itaguara & Muito Baixo & Baixo \\
\hline Itatiaiuçu & Muito Baixo & Médio \\
\hline Jaboticatubas & Muito Baixo & Baixo \\
\hline Juatuba & Médio & Alto \\
\hline Lagoa Santa & Médio & Alto \\
\hline Mário Campos & Baixo & Médio \\
\hline Mateus Leme & Baixo & Médio \\
\hline Matozinhos & Médio & Alto \\
\hline Nova Lima & Alto & Muito Alto \\
\hline Nova União & Muito Baixo & Baixo \\
\hline Pedro Leopoldo & Médio & Médio \\
\hline Raposos & Baixo & Médio \\
\hline Ribeirão das Neves & Muito Alto & Muito Alto \\
\hline Rio Acima & Baixo & Médio \\
\hline Rio Manso & Muito Baixo & Muito Baixo \\
\hline Sabará & Alto & Alto \\
\hline Santa Luzia & Alto & Alto \\
\hline São Joaquim de Bicas & Baixo & Alto \\
\hline São José da Lapa & Médio & Médio \\
\hline Sarzedo & Médio & Alto \\
\hline Taquaraçu de Minas & Muito Baixo & Muito Baixo \\
\hline Vespasiano & Alto & Muito Alto \\
\hline
\end{tabular}

Fonte: Diniz; Andrade (2015, p. 136). 


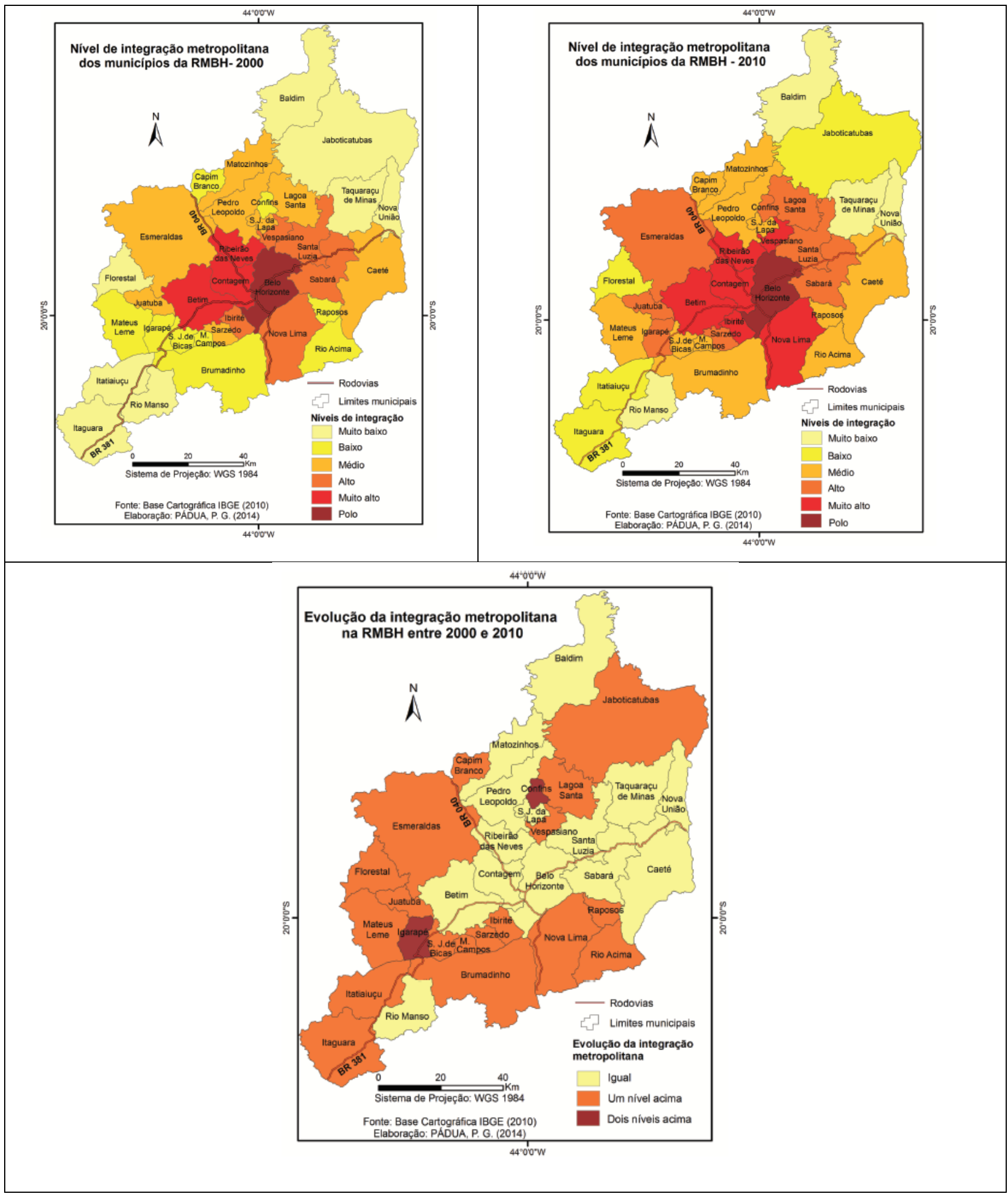

Figura 2 - Nível de integração metropolitana (2000-2010).

Fonte: Diniz; Andrade (2015, p. 139-141).

Conforme se vê, houve significativa expansão nos níveis de integração metropolitana na RMBH. Em 2000, apresentava-se latente a relação direta entre a intensidade das interações entre municípios e suas distâncias em relação ao polo. Tal correlação mostra-se ainda mais acentuada no Vetor Oeste, com altos níveis de integração com os municípios Contagem e Betim, bem como em 
parte do Vetor Norte Central, com destaque para o município dormitório Ribeirão das Neves. Destacam-se também a sudeste a noroeste com altos níveis de integração, os municípios Ibirité, Nova Lima, Sabará, Santa Luzia e Vespasiano. Em 2010 há uma evolução na integração metropolitana. Todos os municípios limítrofes ao polo Belo Horizonte, com exceção de Santa Luzia e Sabará, passaram a apresentar o mais alto nível de integração (DINIZ; ANDRADE, 2015).

O mapa comparativo de 2010-2000 apresenta as evoluções em termos de intensificação de interações: no Vetor Norte da RMBH, marcado principalmente por Confins, Lagoa Santa e Jaboticatubas; outro perpassando pela porção à sudeste de Belo Horizonte, passando pelo Sul até a Noroeste do polo metropolitano, composto pelos municípios (Raposos, Nova Lima, Rio Acima, Ibirité, Sarzedo, Brumadinho, Mário Campos, São Joaquim de Bicas, Itaguara, Itatiaiuçu, Mateus Leme, Juatuba, Igarapé, Juatuba, Mateus Leme, Florestal, Esmeraldas e Capim Branco) (DINIZ; ANDRADE, 2015).

Como justificativas do aumento de interações, tem-se que no Vetor Sul há intensificação da ocupação dos condomínios pela população de média e alta renda; no Vetor Oeste, pela influência da atividade industrial que continua a atrair população de baixa renda, para além dos municípios de Betim e Contagem, como Mário Campos e Sarzedo, além de Esmeraldas no Vetor Norte Central; no Vetor Norte e Norte Central as interações decorrem dos altos investimentos públicos como a Linha Verde ligando Belo Horizonte ao aeroporto de Confins e a transferência do centro administrativo estadual para o norte do município de Belo Horizonte, na divisa com Vespasiano e Santa Luzia, que atraíram investimentos e contingentes populacionais de média e alta renda para condomínios da região, como em Lagoa Santa e de baixa renda para os inúmeros loteamentos (DINIZ; ANDRADE, 2015).

Em termos da expansão urbana metropolitana, a RMBH possuía na década de 1970 uma população aproximada de 1,8 milhão, atingindo 4.883 .970 habitantes em 2010, considerando-se o número de 34 municípios nesta análise. No período, houve elevação do ritmo de crescimento populacional até o período 1960-1970, quando a RMBH alcança o ápice de seu crescimento (6,32\% ao ano), e, a partir do qual apresenta um declínio de crescimento induzido, inicialmente, pela redução do ritmo de crescimento de Belo Horizonte e, posteriormente, pela redução do próprio ritmo de crescimento de seus demais municípios. Os motivos que explicam esse comportamento são a redução da taxa de fecundidade observada em todo o país desde os anos 1960; o enfraquecimento da capacidade de atração populacional ${ }^{1}$, e o aumento do seu poder de expulsão populacional (SOUZA, 2008; SOUZA, 2015).

\footnotetext{
${ }^{1}$ Embora a RMBH continue se destacando, em Minas Gerais, como a maior receptora líquida dos migrantes inter e intraestaduais (SOUZA, 2015).
} 
Segundo Fernandes e Canettieri (2015), desde 1940 a população de Belo Horizonte representava mais de $50 \%$ do volume total de pessoas da RMBH passando de $70 \%$ da população total em 1960. Entretanto, a partir desse período, a participação de Belo Horizonte vai se reduzindo até ficar, em 2010, abaixo de 50\% da população da região metropolitana.

No período 2000-2010, o ritmo de crescimento médio anual foi de 1,15\%, sendo que a maior parte desse crescimento (74,02\%) deve ser atribuído à dinâmica demográfica dos municípios do entorno que cresceram juntos a um ritmo médio anual de 1,70\%, enquanto o crescimento de Belo Horizonte foi de apenas 0,59\% ao ano (SOUZA, 2015).

Ainda segundo Souza (2015), grande parte do ritmo de crescimento do entorno relacionase às migrações intrametropolitanas. Nestes termos:

Belo Horizonte continua se destacando como a principal origem dos migrantes intrametropolitanos e os Vetores Oeste (um espaço de emprego) e Norte Central (um espaço de residência principalmente de população de baixo nível de renda) permanecem como as principais áreas de destino. Em todos os vetores, os municípios que estabelecem os mais altos níveis de integração com o polo são os principais receptores dos emigrantes intrametropolitanos de Belo Horizonte. No Vetor Oeste sobressaem Contagem e Betim; e, no Norte Central, Ribeirão das Neves (SOUZA, 2015, p. 207).

Em termos da mobilidade pendular, os municípios (e vetores) que mais recebem emigrantes intrametropolitanos de Belo Horizonte são os mesmos que se destacam como as principais origens dos fluxos pendulares por motivo trabalho e estudo. Nesse caso, Belo Horizonte permanece como a principal área de absorção desses trabalhadores e estudantes, seguido por Contagem e Betim, no Vetor Oeste que, apesar de se destacarem como importantes áreas de absorção, apresentam saldos pendulares negativos (SOUZA, 2015).

Segundo Souza (2015) os fluxos pendulares ocorrem principalmente por motivo de trabalho (homens jovens) e estudo (mulheres jovens). Em relação às condições socioeconômicas, predominam os baixos níveis de escolaridade e rendimento, mas as significativas diferenças entre os fluxos refletem a organização social do território metropolitano. Neste caso, há características determinantes em relação aos vetores de fluxo pendular:

a) o vetor sul com presença baixa de trabalhos pouco qualificados e maior presença de trabalhadores com maior escolaridade e rendimentos (elite intelectual e elite dirigente), e baixos índices de informalidade;

b) o vetor oeste refere-se ao principal corredor industrial da $\mathrm{RMBH}$, principalmente devido às cidades de Contagem e Betim;

c) no vetor leste destaca-se Sabará com loteamentos destinados a população de baixa renda;

d) no vetor norte destaca-se a implantação de condomínios para classes média e alta; 
e) o vetor norte central contempla os trabalhadores pendulares menos qualificados - chamando a atenção o número relativamente alto de indivíduos sem instrução/fundamental incompleto - e mais mal remunerados de toda a RMBH. É nesse fluxo que se observam os mais elevados graus de informalidade, as menores rendas médias e medianas.

Sobre as atividades econômicas de Belo Horizonte, é importante citá-las correlacionando com o contexto da região metropolitana, devido ao grau de integração com os municípios vizinhos. Considerando a gênese de Belo Horizonte e a evolução história da formação da RMBH é possível entender a estrutura econômica da região. A atividade terciária se concentra em Belo Horizonte enquanto a atividade secundária concentra-se principalmente nos demais municípios da RMBH.

Em que pese as mudanças recentes de reestruturação produtiva, abertura comercial e ganho de hegemonia das políticas neoliberais com diminuição da participação estatal no planejamento e indução da expansão econômica, há pouca diversificação com maior aprofundamento da especialização setorial, com presença da continuidade do crescimento do setor primário exportador (minerais), com exportação de bens primários, produção de bens de consumo duráveis para o mercado interno e expansão do terciário, acompanhando uma tendência nacional. Assim, os prognósticos para a economia da RMBH não indicam saltos qualitativos a novos patamares de sustentabilidade e inclusão social (ANDRADE; MENDONÇA; DINIZ, 2015).

\section{MATERIAIS E MÉTODOS}

Neste trabalho, a fonte dos dados foi documentação indireta, por meio de boletins de ocorrência policial, denominados Registro de Evento de Defesa Social (REDS), para os quais se elaborou um banco de dados de criminalidade para Minas Gerais com recorte temporal de 2011 a 2013, obtidos do armazém de dados do REDS.

Considerando o objetivo do trabalho de análise de casos individuais, foi feita a seleção dos indivíduos aqui considerados como criminosos em série $^{2}$ (registros policiais de delitos cometidos de maneira reiterada, por um mesmo autor).

A seleção dos indivíduos foi feita a partir dos seguintes critérios, considerando os registros de 01 de janeiro de 2011 a 31 de dezembro de 2013: indivíduos registrados em ao menos 04 boletins de ocorrência (REDS) no período, tendo como recorte espacial o cometimento de delitos no município de Belo Horizonte. Entre os autores de delito que compõem o corpo da pesquisa, alguns cometeram diversos outros delitos fora do município de Belo Horizonte. Entretanto, por uma

\footnotetext{
${ }^{2}$ Definição genérica que engloba diversos tipos de criminosos que compartilham de uma mesma característica que é a ação em série, sendo este conceito o de "infrator em série" (FARIA; DINIZ, 2018).
} 
decisão metodológica, foram apenas considerados no trabalho os eventos praticados dentro dos limites municipais. Para cada autor de delito foi atribuído um código numérico sequencial, a fim de suprimir a identidade pessoal.

Para se atingir os objetivos propostos nesta pesquisa, foram coletados os seguintes dados:

a) número de criminosos em série: 114 indivíduos;

b) ocorrências perpetradas por criminosos em série: 1259 ocorrências;

c) endereços dos criminosos em série: 317 pontos;

d) ocorrências com locais de residência válidos: 993 ocorrências.

Para a coleta dos locais de residência, foi feita a pesquisa das ocorrências do endereçamento dos autores de delito. Considerando-se que este parâmetro não possui georreferenciamento no próprio boletim de ocorrência, a inserção dos dados de coordenadas geográficas destes locais foi feita manualmente, buscando-se o georreferenciamento com precisão de quadra para os endereços válidos, utilizando-se a base de arruamentos e endereços da Empresa de Informática e Informação do Município de Belo Horizonte (PRODABEL) em SIRGAS.

Para os indivíduos em que havia algum endereço inválido, mas com outro boletim de ocorrência registrado em endereço diverso, excluiu-se o endereço inválido. Para os endereços indicados dos autores fora de Belo Horizonte utilizou-se a base Google para geocodificação.

\section{DISCUSSÃO DOS RESULTADOS}

Em Belo Horizonte, no período de 2011 a 2013, foram praticados 1259 eventos por 114 criminosos habituais, sendo no mínimo quatro eventos perpetrados no município.

\subsection{Categorias de crimes/contravenções penais}

A fim de se identificar os eventos de defesa social cujos autores sejam recorrentes na prática delituosa em Belo Horizonte no período de 2011 a 2013, descrevem-se as características das ocorrências criminais cometidas pelos criminosos habituais, conforme Tabela 2.

Com objetivo de identificar o perfil dos criminosos habituais em termos de produtividade individual, foi representado na sequência, o número de eventos perpetrados por cada um dos indivíduos que compõem o escopo do trabalho. 
Tabela 2 - Frequência de eventos de criminosos habituais por categoria (tipologia criminal) Belo Horizonte - 2011 a 2013.

\begin{tabular}{|c|c|c|}
\hline \multirow{2}{*}{ Categoria } & \multicolumn{2}{|c|}{ Frequência } \\
\hline & Absoluta & Relativa \\
\hline Contra o Patrimônio & 796 & $63 \%$ \\
\hline Entorpecentes (Uso) & 111 & $9 \%$ \\
\hline Entorpecentes (Tráfico) & 98 & $8 \%$ \\
\hline Contravenção Penal & 94 & $7 \%$ \\
\hline Contra a Liberdade Individual & 61 & $5 \%$ \\
\hline Lesões Corporais & 37 & $3 \%$ \\
\hline Contra a Administração & 21 & $2 \%$ \\
\hline Armas & 9 & $1 \%$ \\
\hline Contra a vida & 8 & $1 \%$ \\
\hline Crime Trânsito & 8 & $1 \%$ \\
\hline Fraude & 7 & $1 \%$ \\
\hline Residual* & 9 & $1 \%$ \\
\hline TOTAL & 1259 & $100 \%$ \\
\hline
\end{tabular}

Fonte: Dados da Pesquisa.

Nota: * Categoria Residual contempla (04 eventos contra a Fé Pública; 03 eventos contra o Meio Ambiente; 1 evento contra a Honra e 1 evento de periclitação da vida).

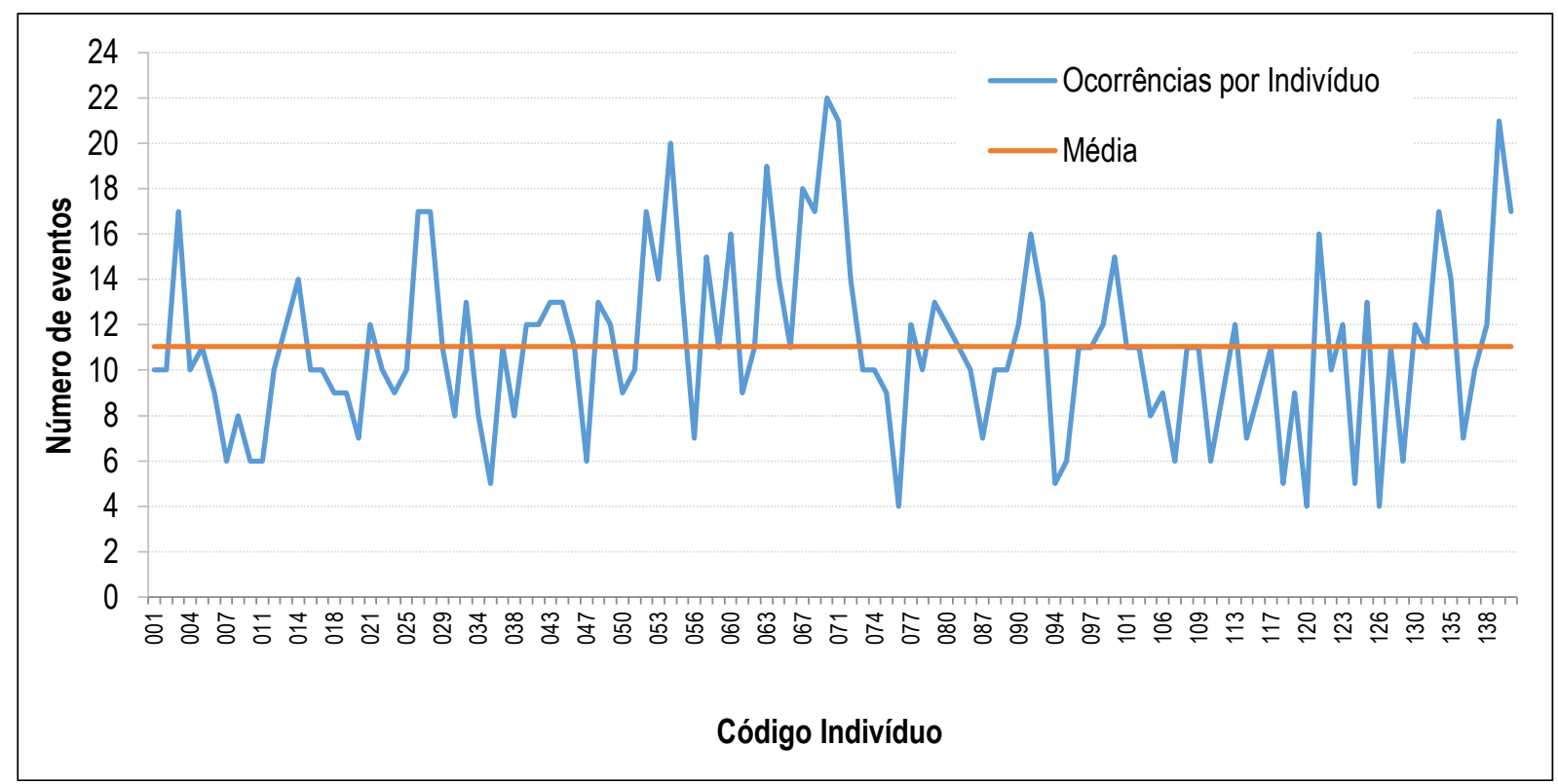

Figura 3 - Frequência de eventos de crimes em série por autor Belo Horizonte - 2011 a 2013.

Fonte: Dados da Pesquisa.

Conforme figura, verifica-se que dos 114 autores de eventos, tem-se no mínimo 4 eventos perpetrados (03 indivíduos) e no máximo 22 eventos. A média de ocorrências por indivíduo é de 11 eventos. 53 indivíduos cometeram até 10 eventos e 61 participaram de 11 ou mais ocorrências. Identifica-se, portanto, que os indivíduos selecionados para comporem a pesquisa são produtivos, sendo que em média foram presos por cometimento de delitos mais de três vezes por ano. 


\subsection{Mobilidade e a dinâmica metropolitana}

Com o objetivo específico de identificar os locais de residência dos criminosos habituais, foi realizada pesquisa nos boletins de ocorrência de cada um dos eventos considerados na presente pesquisa.

Tabela 3 - Eventos que possuem endereços de residência dos autores de delito.

\begin{tabular}{c|c|c}
\hline Endereço & Quantidade & $\mathbf{\%}$ \\
\hline Endereços válidos & 993 & 79 \\
Morador de rua & 153 & 12 \\
Não Informado & 113 & 9 \\
TOTAL & $\mathbf{1 2 5 9}$ & $\mathbf{1 0 0}$ \\
\hline \multicolumn{2}{c}{ Fonte: Dados da Pesquisa. }
\end{tabular}

Das 1259 ocorrências analisadas, 993 possuíam endereços válidos para as residências dos autores, sendo 307 domicílios para os 114 autores. Desta feita, alguns autores possuíam endereços distintos cadastrados em boletins de ocorrência diferentes, em 113 boletins de ocorrência os autores de delito não informaram o endereço e 153 (12\% do total de eventos) eram moradores de rua, não possuindo residência fixa.

Tabela 4 - Localidade de domicílio do criminoso em série.

\begin{tabular}{c|c|c|c}
\hline $\begin{array}{c}\text { Município do domicílio } \\
\text { do Autor }\end{array}$ & $\begin{array}{c}\text { Quantidade } \\
\text { domicílios }\end{array}$ & $\begin{array}{c}\text { Ocorrências de } \\
\text { autor domiciliado }\end{array}$ & $\begin{array}{c}\text { \% de } \\
\text { ocorrências }\end{array}$ \\
\hline Belo Horizonte & 243 & 783 & $79 \%$ \\
Ribeirão das Neves & 10 & 68 & $7 \%$ \\
Santa Luzia & 7 & 29 & $3 \%$ \\
Contagem & 10 & 23 & $2 \%$ \\
Ibirité & 15 & 18 & $2 \%$ \\
Sabará & 3 & 15 & $2 \%$ \\
Vespasiano & 3 & 11 & $1 \%$ \\
Barão de Cocais & 1 & 11 & $1 \%$ \\
São José da Lapa & 1 & 8 & $1 \%$ \\
Itabira & 2 & 7 & $1 \%$ \\
Ipatinga & 1 & 5 & $1 \%$ \\
Itapecerica & 2 & 4 & $0 \%$ \\
Montes Claros & 1 & 3 & $0 \%$ \\
Corinto & 2 & 2 & $0 \%$ \\
São Joaquim de Bicas & 1 & 1 & $0 \%$ \\
Mateus Leme & 1 & 1 & $0 \%$ \\
Sarzedo & 1 & 1 & $0 \%$ \\
Igarapé & 1 & 1 & $0 \%$ \\
Juatuba & 1 & 1 & $0 \%$ \\
Matozinhos & 1 & 1 & $0 \%$ \\
\hline
\end{tabular}

Fonte: Dados da Pesquisa. 
Conforme a Tabela, Belo Horizonte, local de cometimento dos delitos, possui o maior número de domicílios dos autores (243 domicílios) que cometeram 79\% dos eventos. A Região Metropolitana de Belo Horizonte (RMBH) possui uma representatividade alta, com presença de 13 municípios, excetuando Belo Horizonte, os quais abrigam 55 domicílios (23\% do total de domicílios) de infratores em série mais atuantes na capital. Estes infratores cometeram 178 delitos dos 993 delitos que possuíam indicação de residência dos infratores, ou seja, 18\% do total.

Destacam-se os municípios de Ibirité com 15 domicílios de autores, os quais foram responsáveis pelo cometimento de $2 \%$ dos delitos; Contagem abriga 10 domicílios, cujos autores cometeram $2 \%$ dos delitos; Ribeirão das Neves também com 10 domicílios, destaca-se pela produtividade dos autores oriundos desse município, com cometimento de $7 \%$ do total dos delitos; Santa Luzia com sete domicílios de autores, responsáveis por 3\% das ocorrências; Sabará conta com três domicílios e 15 ocorrências $(2 \%)$ e Vespasiano com registro de três domicílios e 11 ocorrências (1\%), outros municípios da RMBH possuem autores que cometeram delitos em Belo Horizonte.

Os dados corroboram com as informações de integração entre os municípios e Belo Horizonte. Dos 13 municípios presentes, conforme classificação mais recente, realizada em 2010, quatro apresentam integração muito alta (Contagem, Ibirité, Ribeirão das Neves e Vespasiano); sete municípios apresentam nível alto de integração com Belo Horizonte (Igarapé, Juatuba, Matozinhos, Sabará, Santa Luzia, São Joaquim de Bicas, Sarzedo) e somente dois apresentam nível médio de integração (Mateus Leme e São José da Lapa).

Destaca-se o aspecto de mobilidade pendular, que aliado aos principais motivos (trabalho e estudo), também se torna representativo em termos de cometimento de delitos. Esse aspecto contribui para a explicação do delito por meio da teoria das atividades rotineiras (COHEN; FELSON, 1979), em que as atividades corriqueiras da população acabam por moldar o comportamento criminal, ou seja, acompanha a tendência de mobilidade da região metropolitana para a capital por motivos legítimos, também pode ocorrer a mesma tendência de deslocamento para realização de atividades ilícitas.

Nesse contexto, destacam-se os municípios do vetor Norte (Vespasiano, Santa Luzia, Ribeirão das Neves) e do Vetor Oeste (Contagem e Ibirité), sendo que a Oeste se tem apenas Sabará. Merece relevo, ainda, a constatação de que o Vetor Sul (onde há predominância de população com melhores condições econômicas) não foi identificada como domicílio de infrator em série mais prolíficos atuantes em Belo Horizonte no período, conforme corpus da pesquisa.

Apontam-se outros municípios da RMBH menos representativos em termos de número de domicílios e de eventos cometidos por autores domiciliados nestas localidades (São José da Lapa, São Joaquim de Bicas, Mateus Leme, Sarzedo, Igarapé, Juatuba e Matozinhos), mas que também se 
referem aos mesmos fluxos pendulares. Outros municípios citados como endereços dos autores fora da RMBH (Itabira, Corinto, Itapecerica, Barão de Cocais, Ipatinga e Montes Claros), devido à distância de Belo Horizonte, permitem inferir que os autores podem até possuir residência (permanente) nessas localidades, conforme indicado nos Boletins de Ocorrência, mas provavelmente utilizam de outros locais para domicílio, não se tratando, enfim, de mobilidade pendular.

\subsection{Os eixos viários}

A distribuição direcional (elipse de desvio padrão) agrega o aspecto do formato da alocação espacial dos eventos, representando também a orientação, além da densidade dos pontos. Dessa forma, contribui para a identificação de tendência de distribuição dos pontos e permite uma análise que leva em consideração a paisagem em que os fenômenos ocorrem.

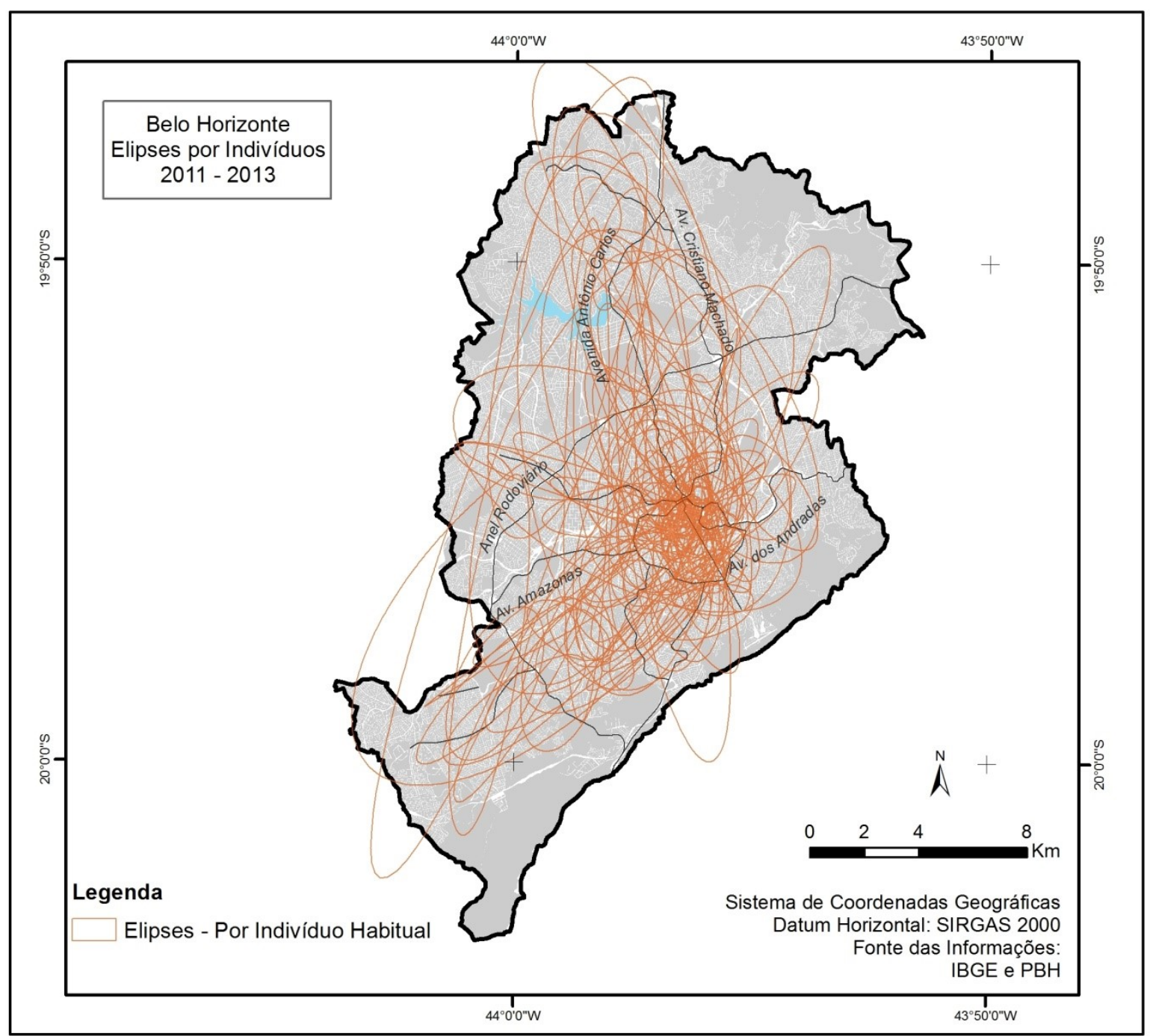

Figura 5 - Mapa de Elipses de Desvio Padrão de Ocorrências por autor criminoso em série Belo Horizonte - 2011-2013.

Fonte: Dados da Pesquisa. 
Cada elipse é determinada por meio de três parâmetros: ângulo de rotação, dispersão ao longo do maior eixo e dispersão ao longo do menor eixo.

Conforme opção metodológica realizada, as elipses foram construídas com um desvio padrão, quer dizer, as elipses compreendem $68 \%$ dos centroides do espaço analisado. Por esse critério, observa-se a abrangência das elipses com grande concentração na região central de Belo Horizonte.

Com a finalidade de correlacionar a distribuição dos eventos com a paisagem urbana, verificou-se a dispersão ao longo do maior eixo e o ângulo de rotação. A dispersão ao longo do maior eixo cobre a maior parte dos principais eixos viários de Belo Horizonte, permitindo inferir que os caminhos (paths) representam um importante elemento de análise na distribuição de eventos criminais de infratores em série, alinhando-se à previsão das teorias de padrão do crime (BRANTINGHAM; BRANTINGHAM, 1993) e das atividades rotineiras (COHEN; FELSON, 1979).

Em termos de ângulo de rotação das elipses, para viabilizar a análise, agrupou-se por faixas de ângulos e elaborou-se a Figura a seguir, contendo as faixas que contém a maior representatividade área coberta pelas elipses.

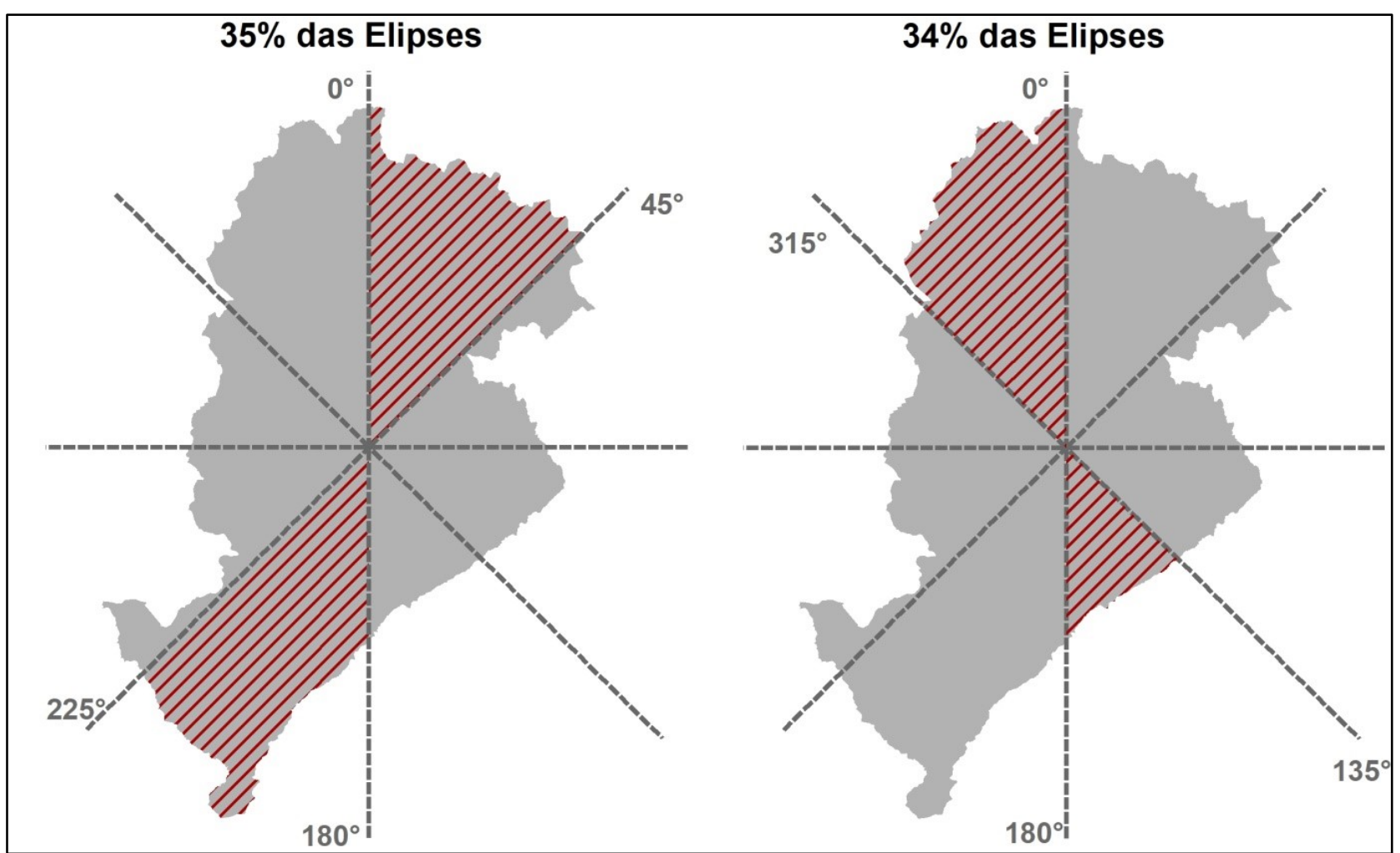

Figura 6 - Representação das áreas cobertas pelas elipses de desvio padrão correspondentes aos ângulos de rotação. Fonte: Elaborado pelos autores.

Assim, o espalhamento dos eventos que define o formato das elipses, ocorre principalmente no sentido Norte-Sul da cidade, possuindo o efeito de atração da região central 
(hipercentro), e acompanhamento radial no sentido dos eixos viários principais do vetor Norte principalmente, Av. Cristiano Machado e Av. Antônio Carlos/Av. Pedro I, que promovem a mobilidade entre Belo Horizonte e cidades da RMBH, no sentido de maior desenvolvimento recente da região.

Por meio das elipses, identifica-se ainda os eixos que ligam aos municípios limítrofes à Nordeste da capital (Sabará e Santa Luzia), no mesmo sentido à Sudoeste (Ibirité e Sarzedo). Na outra porção, à Noroeste, tem-se contiguamente a integração com Vespasiano, Ribeirão das Neves e Contagem). Todos esses municípios conurbados compõem os maiores níveis de integração metropolitana (integração muito alta ou alta) e o delineamento das vias de integração confirmam o papel dos caminhos na teoria do padrão criminal (BRANTINGHAM; BRANTINGHAM, 1993).

\section{CONCLUSÕES}

Foi possível rever como a criação de Belo Horizonte, calcada em ideais republicanos, e limitada inicialmente pela área planejada definida pelo sítio ideal de ocupação, arquitetada para centralizar as atividades políticas, administrativas e de comércio e serviços, acabou por ocorrer uma expansão inversa do planejado, no sentido periferia-centro, o que favoreceu a ocupação de áreas carentes em termos estruturais por grupos de baixa renda, devido à grande valorização das terras "urbanizadas", que foram ocupadas pelas elites, o que acabou por promover a desigualdade social. A partir de 1950 ocorre o processo de metropolização com espraiamento da ocupação para além dos limites municipais.

A organização do espaço urbano apresenta o "centro histórico" com a ocupação maciça do setor de comércio e serviços, além de importantes equipamentos públicos, com aparecimento de centros descontínuos e presença de eixos radiais de transporte que promoveu a ligação do hipercentro de $\mathrm{BH}$ com os seus vetores de expansão. O eixo de industrialização no sentido do Vetor Oeste determinou uma ocupação desta porção pelas classes operárias, no Vetor Sul com ocupação das classes elitizadas; Vetor Norte pelas classes menos favorecidas, porém sendo o eixo de expansão mais recente, alavancado por intervenções públicas como a implantação do centro administrativo do Estado, modernização do eixo viário Linha Verde e do aeroporto internacional no município de Confins.

A lógica de ocupação acabou por se perpetrar pela RMBH com expansão das classes mais abastadas no sentido do Vetor Sul, principalmente em Nova Lima, além de cidades-dormitório no Vetor Norte Central para trabalhos de baixa renda, como a cidade de Ribeirão das Neves e de classe média, como Lagoa Santa. 
Em termos da dinâmica econômico-espacial, tem-se a posição privilegiada da RMBH na economia nacional com destaque para os setores econômicos de comércio e serviços e incremento nos últimos anos do grau de formalização do emprego.

Nos últimos anos há uma maior integração entre os municípios da RMBH, com maior participação em termos populacionais das cidades do entorno, mas com manutenção da primazia em termos econômicos do polo regional, Belo Horizonte.

A lógica da instalação e desenvolvimento tanto da capital quanto da região metropolitana, justifica a mobilidade pendular da população presente nos municípios circunvizinhos para Belo Horizonte e replica-se para a distribuição espacial do fenômeno criminal. Da mesma forma que os motivos legítimos atraem parcela importante da população para realizarem suas atividades no centro político, econômico e cultural da região, ocorre também o deslocamento de infratores contumazes para cometerem seus delitos em Belo Horizonte.

Por meio deste trabalho, observou-se que $18 \%$ dos delitos perpetrados pelos infratores em série mais produtivos em Belo Horizonte estão domiciliados na RMBH, que abriga 22\% das residências desses autores. Os municípios com maiores índices de integração com Belo Horizonte também são os mais representativos em termos da presença de infratores em série que atuam na capital.

A pesquisa descortina aspectos ainda não abordados em trabalhos anteriores, preenchendo uma lacuna em termos acadêmicos e permite colaborar com o planejamento urbano e regional, numa perspectiva interdisciplinar por meio de análise espacial e técnicas típicas da geografia teorética-quantitativa, com suporte teórico da criminologia ambiental, uma vez que, a partir do conhecimento produzido, identifica-se a necessidade de integração entre agências dedicadas à prevenção e repressão criminal, bem como o alinhamento e compartilhamento de informações criminais, pois a dinâmica populacional não está adstrita a divisões formais de regiões de planejamento/jurisdição.

\section{AGRADECIMENTOS}

Os autores agradecem à Comissão de Aperfeiçoamento de Pessoal de Nível Superior (CAPES) pela bolsa de estudos de doutorado que viabilizou a realização da pesquisa e à FAPEMIG pelo apoio financeiro - PPM 00705-16.

\section{REFERÊNCIAS}

ACCIOLY, V. M.; NOGUEIRA, C. M. L. Mobilidade e Metropolização: o caso da Região Metropolitana de Fortaleza. Revista Geográfica de América Central, v. 2, p. 1-15, 2011. 
BALBIM, R. N.; BECKER, M. F.; COSTA, M. A; MATTEO, M. Desafios contemporâneos na gestão das regiões metropolitanas. Revista Paranaense de Desenvolvimento-RPD, n. 120, p. 149$176,2012$.

BRANTINGHAM, P. J.; BRANTINGHAM, P. L. Patterns in crime. 1. ed. New York: Macmillan, 1984. 402p.

BRANTINGHAM, P.; BRANTINGHAM, P. Nodes, paths and edges: Considerations on the complexity of crime and the physical environment. Journal of Environmental Psychology, v. 13, n. 1, p. 3-28, 1993.

BRANTINGHAM, P.; BRANTINGHAM, P. Environmental criminology. In: CULLEN, F.T.; WILCOX, P. Encyclopedia of Criminological Theory. Beverly Hills: Sage. 1981. p. 663-668.

BRANTINGHAM, P.; BRANTINGHAM, P. Notes on the geometry of crime. In: BRANTINGHAM, P.; BRANTINGHAM, P. Environmental Criminology. Waveland: Prospect Heights, 1991. p. 27-54.

BRITO, F. Urbanização, metropolização e mobilidade espacial da população: um breve ensaio além dos números. 1. ed. Brasília: CEPAL, 2007. 8p.

BRITO, F.; SOUZA, J. Expansão urbana nas grandes metrópoles: o significado das migrações intrametropolitanas e da mobilidade pendular na reprodução da pobreza. São Paulo em Perspectiva, v. 19, n. 4, p. 48-63, 2005.

BRITO, F.; SOUZA, R. Migração e mobilidade na expansão da região metropolitana de Belo Horizonte: o caso de Nova Lima. 1. ed. Belo Horizonte: Ed. da UFMG, 2005b. 345p.

BROWN, D. L.; CHAMPION, T.; COOMBES, M.; WYMER, C. The Migration-commuting nexus in rural England. A longitudinal analysis. Journal of Rural Studies, v. 41, p. 118-128, 2015.

BÜTTNER, B.; ZHAO, J.; THIERSTEIN, A.; WULFHORST, G.; FÖRSTER, A.; STERZER, L. When growth stresses development. Interdependencies between housing, employment and mobility in the Munich metropolitan region. In: WORLD CONGRESS RSAI, 10., 2014. Bangkok. Proceedings... Bangkok: RSAI, 2014. p. 1-20.

CARVAlHO, I. M. M.; ALMEIDA, P. H.; AZEVEDO, J. S. G. Dinâmica Metropolitana e Estrutura Social em Salvador. Tempo Social, v. 13, n. 2, p. 89-114, 2001.

CHAMPION, T.; COOMBES, M.; BROWN, D. L. Migration and longer-distance commuting in rural England. Regional studies, v. 43, n. 10, p.1245-1259, 2009.

CHEN, C. Extended commuting and migration in the Taipei metropolitan area. Journal of Population studies, n. 15, p. 161-183, 1992.

COHEN, L.; FELSON, M. Social change in crime rates trends: A routine activity approach. American Sociological Review. v. 44, n. 4, p. 588-608. 1979.

COMINI, L.; NOGUEIRA, M.; LOBO, C.; GARCIA, R. A. Dispersão espacial da população na Região de influência de Belo Horizonte - análise dos municípios de pequeno porte. In: ENCONTRO NACIONAL DE ESTUDOS POPULACIONAIS. 9., 2014, São Pedro. Anais... São Pedro: ABEP, 2014, p. 1-13. 
DELGADO, P.; DESCHAMPS, M.; MOURA, R. E.; CINTRA, A. Mobility In: Brazilian Metropolitan Regions: Migration And Commuting Processes. In: BALBIM, R.; KRAUSE, C.; LINKE, C. C. City and movement: mobilities and interactions in urban development. Brasília: IPEA, 2016. p. 215-237.

DINIZ, A. M. A.; ANDRADE, L. T. Metropolização e hierarquização das relações entre os municípios da RMBH. In: ANDRADE, L.T.; MENDONÇA, J. G; DINIZ, A. M. A Belo Horizonte: transformações na ordem urbana. Rio de Janeiro: Letra Capital, 2015.

DINIZ, A. M. A.; MENDONÇA, J. G. Nota metodológica: configuração dos vetores de expansão da RMBH. In: ANDRADE, L. T.; MENDONÇA, J. G.; DINIZ, A. M. A. Belo Horizonte: transformações na ordem urbana. Rio de Janeiro: Letra Capital, 2015.

ECK, J.; WEISBURD, D. Crime and Place: Crime Prevention Studies.1 ed. New York: Criminal Justice Press, 1995. 363p.

ELIASSON, K.; LINDGREN, U.; WESTERLUND, O. Geographical labour mobility: migration or commuting?. Regional Studies, v. 37, n. 8, p. 827-837, 2003.

FARIA, A. H. P.; DINIZ, A. M. A. Criminosos em série. Revista Brasileira de Segurança Pública, v. 13, n. 1, p. 35-58, 2019.

FELSON, M. Ecology of crime. Encyclopedia of crime and justice, v. 2, p. 665-670, 1983.

FERNANDES, A. S. A.; ARAÚJO, S. M V. G. A criação de municípios e a formalização de regiões metropolitanas: os desafios da coordenação federativa. Revista Brasileira de Gestão Urbana, v. 7. n. 3, p. 295-309, 2015.

FERNANDES, D.; CANETTIERI, T. A. Região Metropolitana de Belo Horizonte e a transição demográfica brasileira. In: ANDRADE, L. T.; MENDONÇA, J. G.; DINIZ, A. M. A. Belo Horizonte: transformações na ordem urbana. Rio de Janeiro: Letra Capital, 2015.

FIRKOWSKI, O. L C. F. Porque as regiões metropolitanas no Brasil são regiões, mas não são metropolitanas. Revista Paranaense de Desenvolvimento-RPD, n. 122, p. 19-38, 2012.

GELAN, A. Commuting, migration, and rural development. ESRC Regional \& Urban Science Annual Conference, University of Strathclyde, 2002. Disponível em: https://mpra.ub.unimuenchen.de/1903/. Acesso em: 22 fev. 2019.

GROSTEIN, M. D. Metrópole e expansão urbana: a persistência de processos insustentáveis. São Paulo em Perspectiva, v. 15, n. 1, p. 13-19, 2001.

HOTZ, E. F. A organização metropolitana pós-constituição de 1988. São Paulo em Perspectiva, v. 14, n. 4, p. 91-98, 2000.

LOBO, C.; GARCIA, R. A.; PINTO, G. Mobilidade e dispersão espacial da população: evidências com base na mobilidade pendular metropolitana. Blucher Social Sciences Proceedings, v. 2, n. 2, p. 16-28, 2015.

LOBO, C.; CARDOSO, L.; DE ALMEIDA, I. L.; GARCIA, R. A. Mobilidade pendular e a integração metropolitana: uma proposta metodológica para municípios da Região Metropolitana de 
Belo Horizonte/MG-2010. Revista Brasileira de Estudos de População, v. 34, n. 2, p. 321-339, 2017.

LUKIĆ, V. Correlation between commuting and migration in daily urban system of Pančevo (Vojvodina, Serbia). Geographica Pannonica, v. 13, n. 1, p. 17-21, 2009.

MARICATO, E. O urbanismo na periferia do capitalismo: desenvolvimento da desigualdade e contravenção sistemática. In: GONÇALVES, M. F. O novo Brasil urbano: impasses, dilemas, perspectivas. Porto Alegre: Mercado Aberto, 1995. p. 261-287.

MARICATO, E. Metrópole na periferia do capitalismo. 1996. 141 f. Monografia (Trabalho de Graduação em Arquitetura - Universidade de São Paulo, São Paulo, 1996.

MARICATO, E. Metrópole, legislação e desigualdade. Estudos Avançados, v. 17, n. 48, p. 151$166,2003$.

MENDONÇA, J. G.; DE MOURA COSTA, H. S.; BORGES, M. R. Organização social do território e formas de provisão de moradia na RMBH. ANDRADE, L. T.; MENDONÇA, J. G.; DINIZ, A. M. A. Belo Horizonte: transformações na ordem urbana. Rio de Janeiro: Letra Capital, 2015.

MEYER, R. M. P. Atributos da metrópole moderna. São Paulo em Perspectiva, v. 14, n. 4, p. 3-9, 2000.

MINAS GERAIS. Instituto de Geociências Aplicadas - IGA. As denominações urbanas de Minas Gerais: cidades e vilas mineiras com estudo toponímico e da categoria administrativa. 2. ed. Belo Horizonte: ALMG, 1997. 230p.

MIRANDA, R. A.; DOMINGUES, E P. Commuting to work and residential choices in the metropolitan area of Belo Horizonte, Brazil. Urban Public Economics Review, n. 12, p. 41-71, 2010.

MONTE, F; REDDING, S. J.; ROSSI-HANSBERG, E. Commuting, migration, and local employment elasticities. American Economic Review, v. 108, n. 12, p. 1-40, 2018.

MOURA, R.; BRANCO, C.; GOMES, M. L.; FIRKOWSKI, O. L. C. Movimento pendular e perspectivas de pesquisas em aglomerados urbanos. São Paulo em Perspectiva, v. 19, n. 4, p. 121 $133,2005$.

MOURA, R.; LIBARDI, D.; BARION, M. I. Institucionalização de regiões metropolitanas: qual o sentido?. Revista Paranaense de Desenvolvimento-RPD, n. 111, p. 129-143, 2011.

MOURA, R.; DELGADO, P.; COSTA, M. A. Movimento Pendular e Políticas Públicas: Algumas possibilidades inspiradas numa tipologia dos municípios brasileiros. In: BOUERI, R.; COSTA, M. A. (Ed.). Brasil em desenvolvimento 2013: estado, planejamento e políticas públicas. Brasília: IPEA, 2013. cap. 22, p. 665-696.

OBSERVATÓRIO DAS METRÓPOLES. Identificação dos espaços metropolitanos e construção de tipologias: relatório da atividade 1. 2004. Projeto Análise das Regiões Metropolitanas do Brasil. Contrato Ministério das Cidades, FASE. Disponível em: http://www.observatoriodasmetropoles.ufrj.br/produtos/produto_mc_1.pdf. Acesso em: 25 jan. 2019. 
PINHO, B. A. T. D.; BRITO, F Fluxos migratórios intrametropolitanos: o caso da região metropolitana de Belo Horizonte, 1970-2010. Texto para discussão, 472. Belo Horizonte: UFMG/CEDEPLAR, 2013. 23p.

PLANO METROPOLITANO - MACROZONEAMENTO DA RMBH. Breve Histórico da Gestão Metropolitana da RMBH. Disponível em: http://www.rmbh.org.br/mzrmbh/ptbr/content/rmbh.htm. Acesso em: 22 abr. 2019.

RAMALHO, H. M. B; BRITO, D. J. M. Migração intrametropolitana e mobilidade pendular: evidências para a região metropolitana do Recife. Estudos Econômicos, São Paulo, v. 46, n. 4, p. 823-877, 2016.

RENKOW, M.; HOOVER, D. Commuting, migration, and rural urban population dynamics. Journal of Regional Science, v. 40, n. 2, p. 261-287, 2000.

RIBEIRO, L. C. Q.; DA SILVA, E. T.; RODRIGUES, J. M. Metrópoles brasileiras: diversificação, concentração e dispersão. Revista Paranaense de Desenvolvimento-RPD, n. 120, p. 177-207, 2012.

SHUAI, X. Does commuting lead to migration?. The Journal of Regional Analysis \& Policy, v. 42, n. 3, p. 237-250, 2012.

SOARES, M. R. M. Migração intrametropolitana e movimentos pendulares na Região Metropolitana de Belo Horizonte: o caso do município de Contagem-1991/2000. 2006. $141 \mathrm{f}$. Dissertação (Mestrado em Demografia) - Centro de Desenvolvimento e Planejamento Regional, Universidade Federal de Minas Gerais, Belo Horizonte, 2006.

SOUSA, M. T. R. Mobilidade e acessibilidade no espaço urbano. Sociedade \& Natureza, v. 17, n. 33, p. 119-129, 2005.

SOUZA, R. G. V.; BRITO, F. A. A expansão urbana da Região Metropolitana de Belo Horizonte e suas implicações para a redistribuição espacial da população: o caso do município de Nova Lima1991/2000. In: ENCONTRO DE ESTUDOS POPULACIONAIS. 15., 2016, Caxambu. Anais... Caxambu: ABEP, 2006. p. 1-21.

THOMAS, I.; ADAM, A.; VERHETSEL, A. Migration and commuting interactions fields: A new geography with community detection algorithm?. Belgeo. Revue belge de géographie, n. 4, 2017.

TONUCCI FILHO, J. B. M. ; MAGALHÃES, F. N. C. ; OLIVEIRA, A. M.; SILVA, H. Estrutura produtiva e mercado de trabalho na Região Metropolitana de Belo Horizonte: formação histórica e perspectivas contemporâneas. In: ANDRADE, L. T.; MENDONÇA, J. G.; DINIZ, A. M. A. Belo Horizonte: transformações na ordem urbana. Rio de Janeiro: Letra Capital, 2015.

Trabalho enviado em $02 / 06 / 2020$ Trabalho aceito em $02 / 06 / 2020$ 